\title{
Development of analytical method for sensitive determination of streptozotocin based on solid phase extraction
}

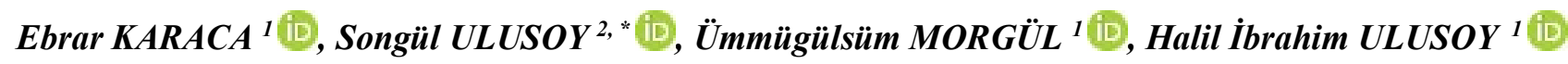 \\ ${ }^{1}$ Cumhuriyet University, Faculty of Pharmacy, Department of Analytical Chemistry, Sivas 58140, TURKEY \\ ${ }^{2}$ Cumhuriyet University, Vocational School of Health Service, Department of Pharmacy, Sivas 58140, TURKEY
}

\begin{abstract}
This study is focused on developing a sensitive analytical method for Streptozotocin (STZ) molecules which is a naturally occurring alkylating antineoplastic agent. It is also known particularly toxic to the insulin-producing beta cells of the pancreas in mammals. With this study, a separation-enrichment method based on solid phase extraction was developed for low levels of STZ. The synthetized material consist of a multi-walled carbon nanotube/ $\mathrm{CuO} / \mathrm{Cu}_{2} \mathrm{O}$ was used as an adsorbent in column type SPE. Experimental variables such as $\mathrm{pH}$, ionic strength, desorption solvent, and other parameters were studied and optimized step by step. Analytical merits were obtained under the optimized conditions: linear range (100.00-1500.00 $\left.\mathrm{ng} \mathrm{mL} \mathrm{m}^{-1}\right)$, limit of detection $\left(28.57 \mathrm{ng} \mathrm{mL}^{-1}\right)$, relative standard deviation (RSD) \% for $250 \mathrm{ng}$ $\mathrm{mL}^{-1}$ of STZ $(<4.2 \%, \mathrm{~N}: 3)$, and pre-concentration factor (125). In order to test accuracy of the method, recovery tests were applied successively by using model solutions.
\end{abstract}

\section{Article info}

History:

Received:09.09.2020

Accepted:11.11.2020

Keywords:

Streptozotocin,

Solid Phase Extraction, Analytical Method

Development

\section{Introduction}

Streptozotocin (2 - deoxy - 2 - ( 3 - ( methy 1 - 3 nitrosoureido ) - D - glucopyranose, STZ) is obtained from Streptomycetes achromogenes type bacteria or synthetic ways. It was used as a narrow-spectrum antibiotic previously, then it has been used frequently to create an experimental diabetes model after its diabetogenic effect has been detected by Rakieten [1]. STZ destroys selectively and irreversibly beta cells of pancreas in mammals. It is also used as a chemotherapeutic drug for some type of cancers and used to produce an animal model for type 1 diabetes in medical researches. It is effective on gram-negative bacteria due to its antibiotic properties. STZ is considered mutagenic, carcinogenic, and possibly teratogenic in human[2-5].

Determination of STZ is generally carried out via HPLC based methods. Most of these methods need a hybrid system like MS. Because adsorption properties of this molecules are very low, it is not easy to follow it by using conventional methods. So, signals of molecule should be improved and separated by using a pre-treatment procedure. It is a challenge to propose a sensitive methods for analytical chemists[6].

From past today, the development of sensitive, selective and easy-to-apply methods in the analysis of complex samples has become an important issue. Actually, although devices and systems with high sensitivity have been already used in analysis of this type molecule, low concentration of analyte and existing of interfering species complicates this analysis $[7,8]$. Separation and enrichment procedures are usually carried out by applying processes such as fractionation, adsorption and extraction on solid surface. The aim of an enrichment is extraction of target molecules or ions from bulk solution having high volume into smaller volume of another solvent [9].

The first experimental applications of solid phase extraction(SPE) have been made since 50 years ago. It was developed as an alternative method for solvent extraction in the mid-1970s and started to be used more widely in the last two decades[10-12]. SPE is used for separation and enrichment, especially in the fields of chemistry, environment, food, cosmetics, biochemistry, medicine, organic synthesis, pharmacology and toxicology. Compared to other SPE techniques, column technique is more extensively used owing to available to automation. The used adsorbent is filled into the column and made ready for passing the sample solution through the column. The success of process depends on feasibility and originality for target molecules[13,14]. 
The analysis of STZ, which has a very limited study even for its direct determination in the literature, is mostly performed with highly complex device systems such as LC-MS. In determination with conventional HPLC systems, the limit of detection does not fall below $1 \mathrm{ppm}$ in most cases. As far as we can tell, there is no any study about determination of STZ after solid phase extraction. Aim of this study, suggestion of a HPLC-PDA based determination method for sensitive analysis of STZ molecules at trace amounts which cannot be analyzed directly with conventional approaches.

\section{Materials and Methods}

\subsection{Chemicals and materials}

Streptozotocin (99.2\%) was purchased from SigmaAldrich (St. Louis, MO, USA). The standard stock solutions of STZ were prepared in methanol by using brown flask. The standart solutions stocked in a dry place and protected from the light. The standard model solution was newly prepared after diluting of the main solutions with methanol. SPE frits and SPE cartridges were purchased from Agilent Technologies (California, USA). Both Triethylene glycol (TEG) and $\mathrm{Cu}\left(\mathrm{CH}_{3} \mathrm{COO}\right)_{2}$ purchased from Sigma-Aldrich were used during the hydrothermal synthesis step of the material. All solvents were used in HPLC grade.

\subsection{Instrumentation}

HPLC analyses were carried out on a Shimadzu HPLC system (Shimadzu, Tokyo, Japan), equipped with a model LC20-AD pump, auto sampler (SIL-20AC), a thermostatic oven (CTO-10 AS), and photodiode array dedector (SPD-M20A). Software (LC Solution, Shimadzu, Tokyo, Japan) was used for data acquisition and detail. An ODS reversed phase packing column $\left(\mathrm{C}_{18}, 250 \times 4.6 \mathrm{~mm}\right.$ i.d., $5 \mu \mathrm{m}$ particle size $)$ were employed for chromatographic separation.

All solvents used were filtered on Millipore-HNWP ( $4 \mathrm{~mm}, 0.45 \mu \mathrm{m}$ ) by using a vacuum pump (Buchi, Switzerland) for the chromatographic system. Then, degassed for $10 \mathrm{~min}$ in an ultrasonic bath.

\subsection{Preperation of $\mathrm{MWCNTs} / \mathrm{Cu}_{2} \mathrm{O}-\mathrm{CuO}$ hybrid nanomaterial}

The used adsorbent in the SPE experiments was syhnetized by using a procedure explanined by Aydin et al. The deailed characterization data were also submitted in their study [15]. Briefly, the synthesis can be explanined as in below.

$0.4 \mathrm{~g}$ of $\mathrm{Cu}\left(\mathrm{CH}_{3} \mathrm{COO}\right)_{2}$ was dissolved in $10 \mathrm{~mL}$ ultra pure water and $30 \mathrm{~mL}$ of TEG (triethylene glycol) was added to this solution. Then, the mixture was completely dissolved on a magnetic stirrer and $0.25 \mathrm{~g}$ of MWCNT was added to solution. Dispersion of particules was facilitated by ultrasonication for $30 \mathrm{~min}$. The obtained product was transferred into for hydrothermal reaction unit composed from a Teflonlined stainless autoclave.This unit having a capacity of $100 \mathrm{~mL}$ was heated throughout at $180^{\circ} \mathrm{C}$ for $12 \mathrm{~h}$. Then, the reaction chamber was waited in order to cool in laboratory conditions. Seperation of the precipitated product was performed by centrifugation at $4000 \mathrm{rpm}$ . The adsorbent washed with ultra pure water and ethanol respectively. Finally, drying process was applied to adsorbent in a vacuum oven throughout at $80^{\circ} \mathrm{C}$ for $6 \mathrm{~h}$. So, has been successfully completed in this process.

\subsection{HPLC conditions for STZ}

The determination parameters of STZ were optimized by HPLC before SPE experiments. In order to achieve this goal the Luna Omega $\mathrm{C}_{18}$ column was used throughtout all determinations. Till, the meaningful peaks for STZ were obtained, experimental optimization were followed step by step. Consequently, the ideal conditions for HPLC were provided with methanol and acetonitrile eluent phases. A summarization of HPLC conditions after optimization was shown in Table 1.

Table 1. HPLC conditions

\begin{tabular}{ll}
\hline HPLC Mode & Isocratic \\
\hline Eluent & $70 \% \mathrm{MeOH} 30 \%$ Acetonitrile \\
Flow Rate & $1 \mathrm{~mL} / \mathrm{min}$ \\
Run Time & $18 \mathrm{~min}$ \\
Colon & $\mathrm{C} 18$-Luna Omega \\
Colon Temperature & $(250 \mathrm{~mm} \times 4.6 \times 5.0 \mu \mathrm{m})$ \\
Injection Volume & $50{ }^{\circ} \mathrm{C}$ \\
\hline
\end{tabular}

The chromatogram has been showed for 3 different STZ concentrations under the determined optimized conditions was given in Figure 1. As can be seen, the peak of the analyte was observed clearly and sharply. Peak height and area increase with concentration as expected.

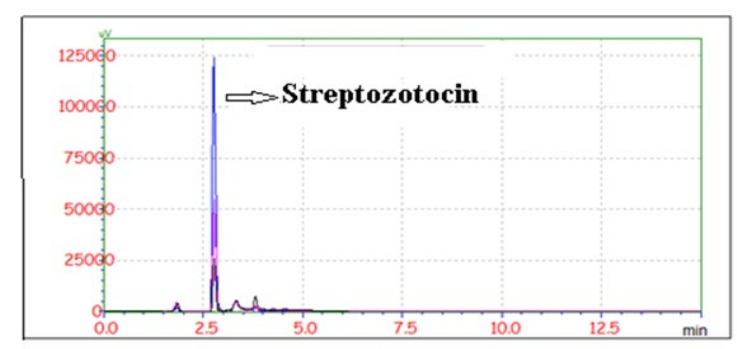

Figure 1. Chromatogram for Streptozocin 
Table 2. shows the direct determination parameters obtained under optimum conditions. As may be seen, significant signals for concentrations lower than 2 ppm were not provided by using these conditions for direct determination. So, a preconcentration method plays important role for sensitive STZ determination.

Table 2. Direct determination results by HPLC before SPE

\begin{tabular}{ll}
\hline Parameter & Streptozotocin \\
\hline Retention Time, min & 2.78 \\
Maximum Absorption Wavelength, $\lambda$ & $229 \mathrm{~nm}$ \\
Calibration Range & $2-50 \mu \mathrm{g} \mathrm{mL}^{-1}$ \\
Limit of Detection (LOD) & $0.57 \mu \mathrm{gL}^{-1}$ \\
$\mathrm{RSD} \%$ & $6.47 \%$ \\
$\mathrm{R}^{2}$ & 0.9968 \\
Number of Repetition & 3 \\
\hline
\end{tabular}

\subsection{Solid-Phase extraction procedures}

$250 \mathrm{mg}$ of the adsorbent material was filled into $1 \mathrm{~mL}$ of SPE cartridge. The upper and lower side of SPE cartridge was fixed by frits. A SPE manifold sysytem was used in order to facilitate filtration of the samples. Pre-condition of SPE cartidges was proved by using $3 \mathrm{~mL}$ of methanol and $3 \mathrm{~mL}$ ultra pure water, respectively. By utilizing acetate buffer solution, $\mathrm{pH}$ of the samples was adjusted to $\mathrm{pH} 4.0 .50 \mathrm{~mL}$ of the sample was passed through the prepared SPE cartridge with at $0.84 \mathrm{~mL} \mathrm{~min}^{-1}$ flow rate.After the absorption, washing of the cartridge was performed by $2 \mathrm{ml}$ of ultra pure water. $400 \mu \mathrm{L}$ of elution solvent (isopropanol) was passed through column for desorption of the retained STZ molecules. The obtained solution was filtered by a PTFE membrane and submitted to the HPLC / PDA system for analysis.

\subsection{Application of the proposed method on model solutions}

The developed and optimized method was applied on the model solutions including STZ at three different concentrations. 100, 250, and $500 \mathrm{ng} \mathrm{mL}^{-1}$ of STZ model solutions were prepared by using stock solutions. After the solutions were filtrated via $0.2 \mu \mathrm{m}$ membrane filter and $10 \mathrm{~mL}$ of this solution was analysed by the developed method.

\section{Results and Discussion}

\section{1. $\mathrm{pH}$ effect}

The acid-base equilibrium for compounds containing functional groups obviously shifts towards neutral or ionic forms when the $\mathrm{pH}$ changes. So, solubility of the target molecules in the sample solution increases or reduces with $\mathrm{pH}$. Thus, most of the analyte molecules are uncharged and readily extracted onto adsorbent surface [16]. Also, $\mathrm{pH}$ value of the medium affects both the reactions between analytes and other species and the enrichment process to be performed in the following steps. In this regard, the optimization of the $\mathrm{pH}$ was carried out by using a buffer series in the range of 2-10. The results obtained were shown in Figure 2. It was observed that the most suitable $\mathrm{pH}$ value for SPE processes was at $\mathrm{pH} 4.00$. So, the $\mathrm{pH}$ of the samples was buffered to $\mathrm{pH} 4$ in the next studies.

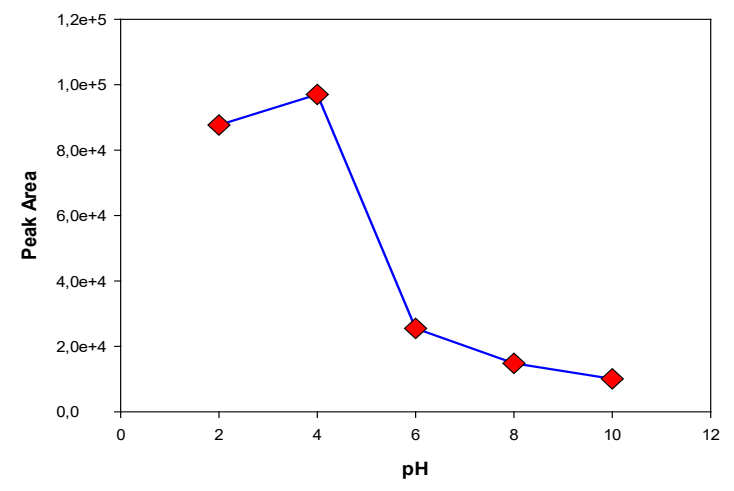

Figure 2. pH effect on the proposed method.

\subsection{Electrolyte effect}

In the developed method, a series experiments were made using $\mathrm{NaCl}$ solution to observe the effect of electrolyte concentration. The solid phase extraction system is affected by the increase of electrolyte concentration of the medium and any change in analyte signals is an important parameter in terms of method stability. Therefore, this parameter needs to be optimized correctly. The operation of the method even in the presence of high electrolyte concentrations is important both for its success in the application phase to real samples and in some cases, the electrodes have a healing effect on the signals by providing the load balance in the medium[17]. In certain circumstances, the signals may be adversely affected as the electrolyte concentration increases. In order to observe all these effects, $\mathrm{NaCl}$ was added to analyte containing model solutions and changes in the peak areas of Streptozotocin were monitored. As seen in Figure 3, although very intense electrolyte concentrations have been reached, distorting effect has not been observed on analyte signals. 


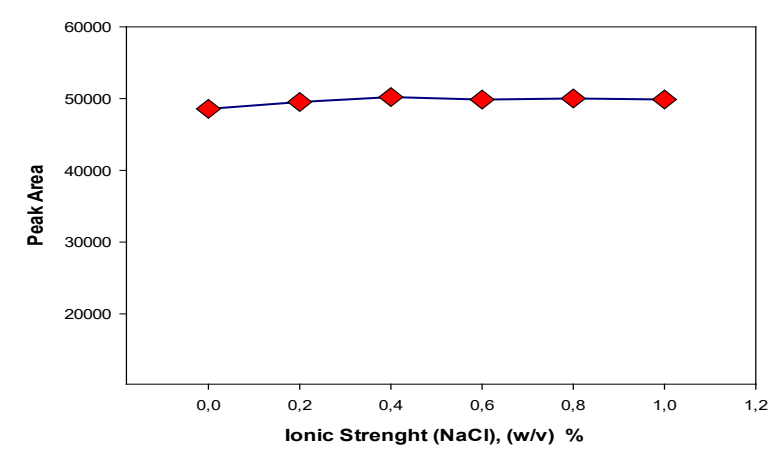

Figure 3. Electrolyte concentration effect on the proposed method

\section{3. Selecting of solvent for desorption process}

The selection of a proper elution solvent has of considerable importance in the developed method. Inasmuch as the elution solvent dramatically effects the enrichment factor, selectivity, and elution efficiency. In SPE, the elution solvent must possess a high affinity toward the target molecule STZ and a rapid kinetics for their quantitative recoveries firstly. After completing the filtration process with SPE manifold, it was time to choose the most suitable solvent for desorption of STZ molecules attached to the solid phase material. An ideal solvent must completely desorb STZ molecules from surface of adsorbent and not be harmful to the device to be determined. While selecting the solvents to be used for this purpose, various solvents were tried in order to be suitable for the eluent phase of the HPLC system and to be strong enough to quantitatively desorption of STZ molecules. For this process: $\mathrm{MeOH}, \mathrm{ACN}$, isopropyl alcohol (IPA), EtOH, water and acetone solvents were applied in desorption process, respectively. The obtained results by considering peaks are are shown in Figure 4.

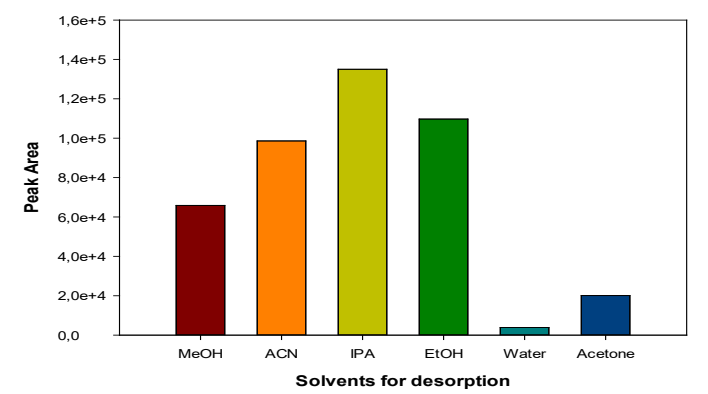

Figure 4. Solvents for desorption process

As illustrated in Figure 4. the highest signal were obtained with IPA solution. Therefore, IPA was used in following steps of optimization. The amount of solvent used to desorb STZ molecules from adsorbent surface directly affects the enrichment factor (EF). In order to obtain a high $\mathrm{EF}$, the volume of the used solvent must be the smallest as possible because volume of the solvent increases, the EF decreases due to dilution. The optimization of solvent volume was performed in the range of 200 and $1000 \mu \mathrm{L}$ of IPA. The best analytical signals (peak area of STZ) was obtained at the volume of $400 \mu \mathrm{L}$ as can be seen Figure 5 . Beyond of this point, there was no meaningful chance at signals.

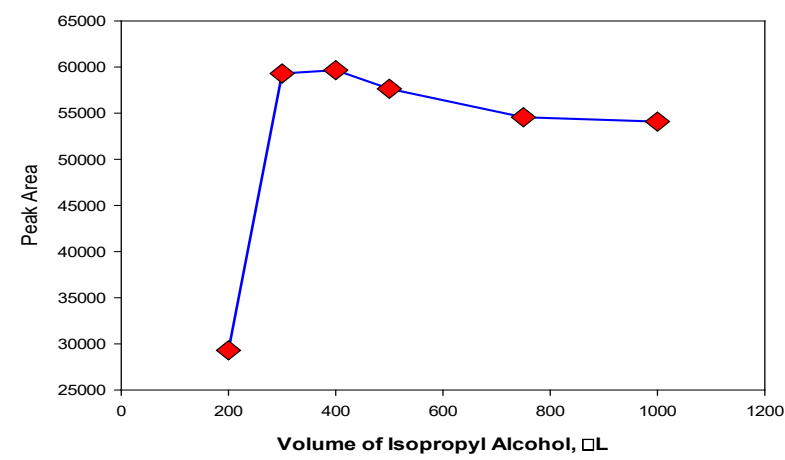

Figure 5. Optimization of solvent volume used for SPE

\subsection{Analytical performance merits of the proposed method}

After determining the most suitable experimental conditions for solid phase extraction, enrichment experiments were applied to different concentrations of streptozotocin solutions to determine the linear working range, as a result of which it was determined that the measured signals changed linearly in the range of $100.00-1500.00 \mathrm{ng} \mathrm{mL}^{-1}$. The calibration curve was given in Figure 6 by applying the development method. As can be seen in Figure 6, the analytical signals increases with the concentrations of STZ proportionally. All analytical parameters of the developed method were collectively presented in Table 3. Limits of detection (LODs) value was found by considering ICH proposals. According to this reference, using the following equation $\mathrm{LOD}=3.3$ $\mathrm{S} / \mathrm{N}$, where $\mathrm{N}=$ noise, $\mathrm{S}=$ signal. The equation $\mathrm{LOQ}=$ $10 \mathrm{~S} / \mathrm{N}$ was used for limitsLimits of quantitation (LOQs) value [18].

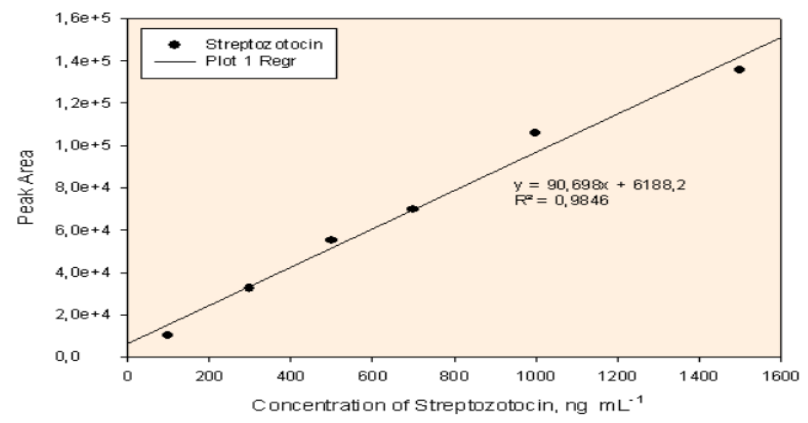

Figure 6. Calibration curve obtained under optimum conditions 
Table 3. Analytical parameters of the proposed method

\begin{tabular}{|c|c|c|}
\hline Parameter & Before SPE & After SPE \\
\hline Linear range & $2000-50000 \mathrm{ng} \mathrm{mL}^{-1}$ & $100.00-1500.00 \mathrm{ng} \mathrm{mL}^{-1}$ \\
\hline Limit of Detection (LOD) & $570.00 \mathrm{ng} \mathrm{mL}^{-1}$ & $28.57 \mathrm{ng} \mathrm{mL}^{-1}$ \\
\hline Limit of Quantification (LOQ) & $1710.00 \mathrm{ng} \mathrm{mL}^{-1}$ & $99.83 \mathrm{ng} \mathrm{mL}^{-1}$ \\
\hline $\mathrm{RSD}(\%)\left(\right.$ for $250 \mathrm{ng} \mathrm{mL}^{-1}$ ) & 6.47 & 4.20 \\
\hline Calibration Sensitivity & 0.954 & 90.698 \\
\hline Correlation Coefficient $\left(\mathrm{R}^{2}\right)$ & 0.9968 & 0.9846 \\
\hline Enrichment Factor ${ }^{\mathrm{a}}$ & - & 95.10 \\
\hline Pre-Concentration Factor ${ }^{\mathrm{b}}$ & - & 125 \\
\hline
\end{tabular}

${ }^{\text {a }}$ Ratio of calibration sensitivity obtained after SPE to calibration sensitivity before SPE

${ }^{b}$ Calculated by taking the ratio of the initial aqueous phase volume $(50 \mathrm{~mL})$ to the volume $(0.4 \mathrm{~mL})$ obtained after enrichment

\subsection{Application of the proposed method to model solutions}

Application of developed method was carried out by using model solutions which are explained in the related section. The recovery results were given in Table 4. Three different model solutions were used in recovery tests.

Table 4 The application of the proposed method on model solutions $(\mathrm{N}: 3)$

\begin{tabular}{|c|c|c|c|c|}
\hline Sample & $\begin{array}{c}\text { Added } \\
\text { ng } \\
\mathrm{mL}^{-1} \\
\end{array}$ & $\begin{array}{l}\text { Found }^{\mathrm{a}} \\
\text { ng mL }\end{array}$ & $\begin{array}{c}\text { RSD } \\
\%\end{array}$ & $\begin{array}{c}\text { Recovery } \\
\%\end{array}$ \\
\hline Model & - & $112.3 \pm 4.0$ & 3.6 & - \\
\hline Solution 1 & 100.0 & $193.6 \pm 6.5$ & 3.4 & 91.2 \\
\hline$\left(100 \mathrm{ng} \mathrm{mL}^{-1}\right)$ & 300.0 & $419.5 \pm 12.6$ & 3.0 & 101.7 \\
\hline Model & - & $265.2 \pm 9.2$ & 3.5 & - \\
\hline Solution 2 & 100.0 & $378.5 \pm 12.8$ & 3.4 & 103.6 \\
\hline$\left(250 \mathrm{ng} \mathrm{mL}^{-1}\right)$ & 300.0 & $523.7 \pm 21.4$ & 4.1 & 92.3 \\
\hline Model & - & $485.8 \pm 14.7$ & 3.0 & - \\
\hline Solution 3 & 100.0 & $575.2 \pm 18.7$ & 3.3 & 98.2 \\
\hline$\left(500 \mathrm{ng} \mathrm{mL}^{-1}\right)$ & 300.0 & $785.4 \pm 24.5$ & 3.1 & 99.9 \\
\hline
\end{tabular}

\section{Conclusions}

A new, sensitive, simple and reliable HPLC based method was developed for the determination of STZ. The present method offers a simple extraction procedure. The proposed SPE-HPLC-PDA procedure allows the reliable analysis of STZ which have not been determined in previously reported analytical method. When we consider it from this perspective even also, it can be concluded that the study is original. It offers a different perspective to the literature in terms of contributing to future studies. The developed method has the advantage of being fast and easy.

\section{Acknowledgment}

This study is thesis of Ebrar Karaca who was graduated from faculty of pharmacy in 2018. The experimental data was collected and arranged by helping with the other authors. Also, experimental studies of this study has been carried out by using project budgets supported by Cumhuriyet University Scientific Research Projects Commission with the ECZ-048 and ECZ-063 codes.

\section{Conflicts of Interest}

The authors state that did not have conflict of interests. 


\section{References}

[1] Rakieten N., Rakieten M.L. and Nadkarnı M.R., Studies on the diabetogenic action of streptozotocin (NSC-37917)., Cancer Chemother. Rep. 29 (1963) 91-98.

[2] Shivanna N., Naika M., Khanum F. and Kaul V.K., Antioxidant, anti-diabetic and renal protective properties of Stevia rebaudiana, $J$. Diabetes Complications. 27 (2013) 103-113.

[3] Furman B.L., Streptozotocin-Induced Diabetic Models in Mice and Rats, Curr. Protoc. Pharmacol. 70 (2015) 5.47.1-5.47.20.

[4] Abdollahi M. and Hosseini A., Streptozotocin, in: Encycl. Toxicol. Third Ed., 2014.

[5] Tesch G.H, Allen T.J., Rodent models of streptozotocin-induced diabetic nephropathy (methods in renal research), Nephrology. 12 (2007) 261-266.

[6] Bhatt H., Saklani S. and Upadhayay K., Antioxidant and anti-diabetic activities of ethanolic extract of Primula Denticulata Flowers, Indones. J. Pharm. 27 (2016) 74-79.

[7] Ulusoy S., Acidereli H., Erdoğan S. and Ulusoy H.I, A new approach to the determination of folic acid at trace levels: Using a Fe(iii)-folic acid complex to amplify analytical signal, $R S C$ Adv. 6 (2016) 40115-40122.

[8] Ulusoy S., Erdogan S., Karaaslan M.G., Ateş B., Ulusoy H.İ, Erdemoglu S., Optimization Of Extraction Parameters For Folic Acid And Antioxidant Compounds From An Edible Plant (Polygonum Cognatum Meissn) Using Pressurized Liquid Extraction (PLE) System, Cumhur. Sci. J. 39 (2018) 1069-1080.

[9] Ulusoy H.İ., Acıdereli H., Ulusoy S. and Erdoğan S., Development of a New Methodology for Determination of Vitamin B9 at Trace Levels by Ultrasonic-Assisted Cloud Point Extraction Prior to HPLC, Food Anal. Methods. 10 (2017) 799-808.

[10] Tuzimski T. and Rejczak T., Application of HPLC-DAD after SPE/QuEChERS with $\mathrm{ZrO}<$ inf $>2</$ inf $>$-based sorbent in d-SPE clean-up step for pesticide analysis in edible oils, Food Chem. 190 (2016) 71-79.
[11] Babić S., Ašperger D., Mutavdžić D., Horvat A.J.M. and Kaštelan-Macan M., Solid phase extraction and HPLC determination of veterinary pharmaceuticals in wastewater, Talanta. 70 (2006) 732-738.

[12] Li Q., Lam M.H.W., Wu R.S.S. and Jiang B., Rapid magnetic-mediated solid-phase extraction and pre-concentration of selected endocrine disrupting chemicals in natural waters by poly(divinylbenzene-co-methacrylic acid) coated $\mathrm{Fe} 3 \mathrm{O} 4$ core-shell magnetite microspheres for their liquid chromatographyta, J. Chromatogr. A. 1217 (2010) 1219-1226.

[13] Kole P.L., Venkatesh G., Kotecha J., Sheshala $\mathrm{R}$., Recent advances in sample preparation techniques for effective bioanalytical methods, Biomed. Chromatogr. 25 (2011) 199-217.

[14] Buszewski B., Szultka M., Past, Present, and Future of Solid Phase Extraction: A Review, Crit. Rev. Anal. Chem. 42 (2012) 198-213.

[15] Aydin F., Yilmaz E., Ölmez E., Soylak M., $\mathrm{Cu}_{2} \mathrm{O}-\mathrm{CuO}$ ball like/multiwalled carbon nanotube hybrid for fast and effective ultrasound-assisted solid phase extraction of uranium at ultra-trace level prior to ICP-MS detection, Talanta. 207 (2020) 120295..

[16] Maham M., Kiarostami V., Waqif-Husain S., Abroomand-Azar P., Saber-Tehrani M., Sharifabadi M.K., Afrouzi H., Shapouri M., Karami-Osboo R., Extraction and determination of cyproheptadine in human urine by DLLME-HPLC method, Iran. $J$. Pharm. Res. 12 (2013) 311-318.

[17] Hey M.J, Jackson D.P., Yan H., The salting-out effect and phase separation in aqueous solutions of electrolytes and poly(ethylene glycol), Polymer 46(8) (2005) 2567-2572.

[18] Agadellis E., Tartaglia A., Locatelli M., Kabir A., Furton K.G., Samanidou V., Mixed-mode fabric phase sorptive extraction of multiple tetracycline residues from milk samples prior to high performance liquid chromatographyultraviolet analysis, Microchem. J. 159 (2020) 105437. 